\title{
Iron fortified follow on formula from 9 to 18 months improves iron status but not development or growth: a randomised trial
}

\author{
Ruth Morley, Rebecca Abbott, Susan Fairweather-Tait, Una MacFadyen,
} Terence Stephenson, Alan Lucas

MRC Childhood

Nutrition Research Centre, Institute of Child Health, 30 Guilford Street, London WC1N 1EH, UK

R Abbott

A Lucas

Menzies Centre for Population Health Research, Tasmania and Clinical

Epidemiology and Biostatistics Unit,

University of

Melbourne

Department of

Paediatrics, Royal

Children's Hospital,

Flemington Road,

Parkville, VIC 3052,

Australia

R Morley

Institute of Food

Research, Norwich

Research Park, Colney,

Norwich, Norfolk

NR4 7UA, UK

$S$ Fairweather-Tait

Stirling Royal

Infirmary, Livilands,

Stirling FK8 2AV, UK

$\mathrm{U}$ MacFadyen

Department of Child

Health, Queens

Medical Centre,

Nottingham NG7 2UH,

UK

T Stephenson

Correspondence to: Dr Morley.

email: morleyr@cryptic.

rch.unimelb.edu.au

Accepted 10 May 1999

\begin{abstract}
Aims-Iron deficiency anaemia is associated, in observational studies, with developmental disadvantage. This study tested the hypothesis that feeding iron supplemented formula from 9 to 18 months of age would improve developmental performance.

Subjects and methods-493 healthy children aged 9 months being fed pasteurised cows' milk were recruited from three UK centres. They were randomised to: cows' milk as before, formula containing $0.9 \mathrm{mg} /$ litre iron, or formula containing $1.2 \mathrm{mg}$ / litre iron, until 18 months of age. Bayley mental and psychomotor developmental indices were measured at $\mathbf{1 8}$ months, as were growth and haematological indices. Results-Children fed iron fortified formula had higher plasma ferritin concentrations, but there were no significant intergroup differences in development or growth.
\end{abstract}

Conclusions-There are no developmental or growth advantages in children given iron supplemented formula, but a benefit for a minority who were anaemic, or the possibility that a benefit may emerge at a later age, cannot be excluded.

(Arch Dis Child 1999;81:247-252)

Keywords: iron; anaemia; development; growth

Iron deficiency anaemia is thought to be a common nutritional deficiency disease in infants and children in developed countries and its prevalence has been estimated at 50\% in less developed countries, ${ }^{12}$ where it is associated with poverty, malnutrition, and disease. Iron fortification of milk formula or weaning foods has been shown to reduce the incidence of iron deficiency anaemia. . $^{3-5}$

Evidence from observational studies suggests that children with iron deficiency anaemia (in some cases after being randomised to receive iron supplementation in clinical trials) suffer a developmental disadvantage, ${ }^{67}$ although this association is confounded by differences between families of children with and without anaemia. ${ }^{8}$ Simeon and GranthamMcGregor reviewed all studies reported up to 1990, and in none of them was the posttreatment developmental score significantly higher in treated than control infants. ${ }^{9}$ In Aukett and colleagues' study of 97 UK children there was no difference in Denver developmental scores between treated and control infants at the end of the intervention period, although the treated children had acquired more new skills. ${ }^{10}$

In a more recent study from Indonesia, 50 children aged 12 to 18 months, with iron deficiency anaemia, were randomly allocated to a placebo or $3 \mathrm{mg} / \mathrm{kg} /$ day iron as ferrous sulphate for four months. ${ }^{11}$ Treated children had a significantly greater mean increase in Bayley motor scale (PDI) scores than controls. No evidence is presented to show whether the change in mental scale (MDI) scores differed significantly.

The results of a randomised trial in Canada of infants from very low income families fed iron fortified versus unfortified formula, show that those fed fortified formula had significantly higher PDI scores at 9 and 12 months. ${ }^{12}$ The effect did not persist to 18 months, but the drop out rate throughout the study was high, $46 \%$ by 18 months, raising the possibility of selection bias.

More recently, 100 inner city infants in the UK already on cows' milk at 7 months were randomised to continued cows' milk or an iron supplemented formula until 18 months of age. ${ }^{4}$ Iron deficiency anaemia was more common in the cows' milk fed group, but no differences were found in Griffiths general quotient (GQ) at 18 months. However, by 24 months of age, the 41 iron supplemented formula fed children had a significantly smaller decline in GQ scores (since enrollment) than the cows' milk fed group (44 infants). ${ }^{13}$ The decline was significantly different only in the personal and social domain.

In view of the uncertainties in this field we conducted a randomised trial of iron supplementation until 18 months in a cohort of healthy term infants already on pasteurised raw cows' milk at 9 months of age. The primary hypothesis was that mean Bayley mental and psychomotor development indices (MDI and PDI) at 18 months would be five points higher in children fed an iron fortified formula between 9 and 18 months than in children fed unsupplemented formula. Secondary hypotheses were that: the use of an iron fortified follow on formula, rather than cows' milk, confers a five point advantage in MDI and PDI; iron supplementation from 9 to 18 months does not influence growth; and iron supplementation from 9 to 18 months improves haematological indices (haemoglobin, ferritin, and transferrin receptor values) at 18 months. 


\section{Methods}

Our study was approved by the research ethics committee in each of the three collaborating UK centres (Leicester, Norwich, and Nottingham) and written informed consent was given by the parents of all participants.

Figure 1 shows the study recruitment and assessment flow diagram. Letters were sent to parents of potential subjects (identified from birth registers) explaining that we were planning to conduct a trial of different types of milk and asking which type their child was currently receiving. At this stage, parents were not told that we planned to recruit cows' milk fed infants. If mothers reported that their infant was fed cows' milk and receiving no formula, they were sent a second letter with information about the trial. Those who agreed to take part were visited at home by a trained research nurse who obtained written informed consent.

Subjects were healthy infants born after 36 or more completed weeks of gestation, weighing $>2500 \mathrm{~g}$, and either singletons or sole survivors from a multiple pregnancy. Children with a disease or impairment known to affect growth or development, evidence of developmental or neurosensory impairment, or a

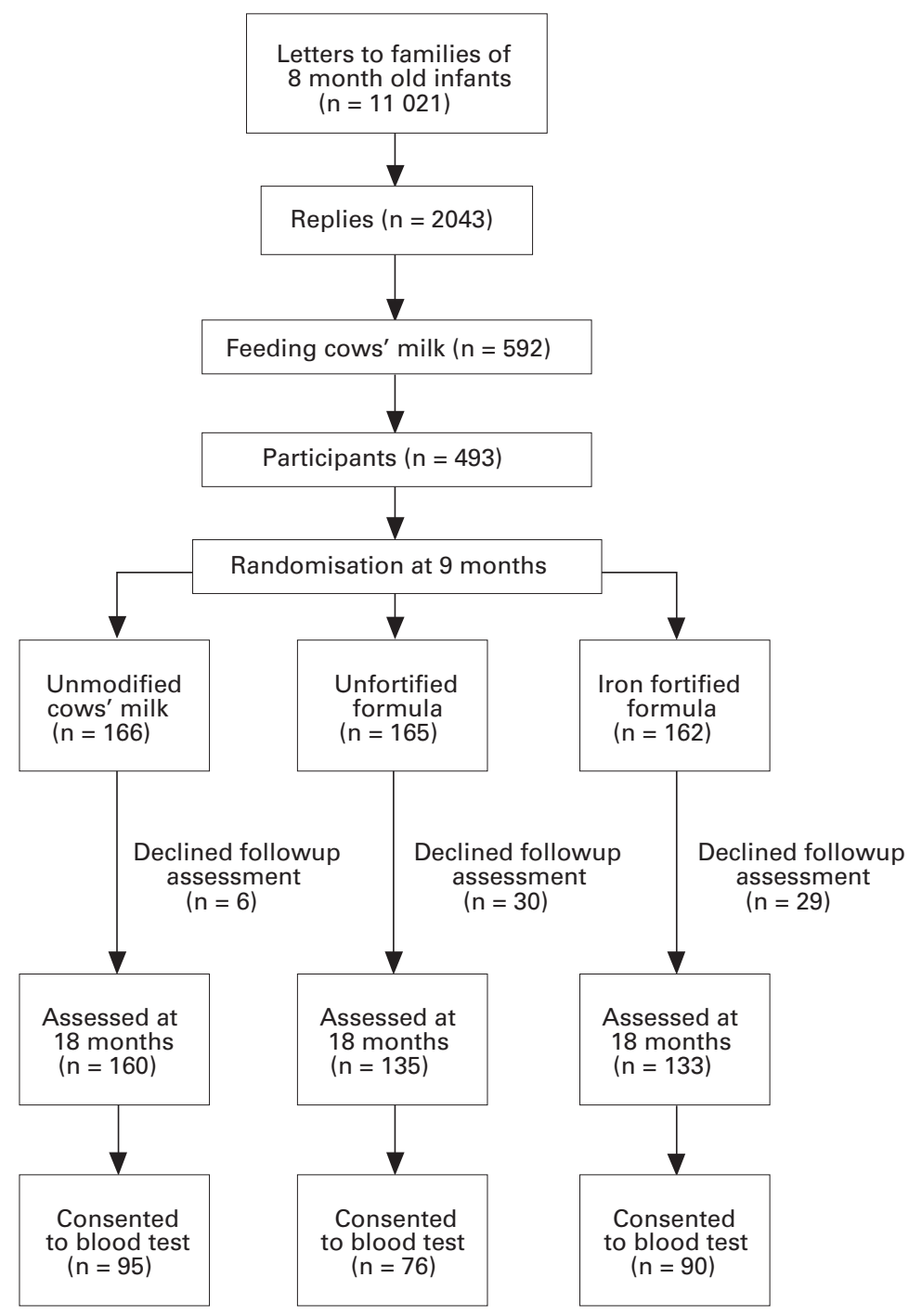

Figure 1 Recruitment to and losses from the study. history of transfusion or iron supplementation, as well as those whose first language was not English, were excluded from the study. The latter was because the Bayley scales, like other developmental tests, have not been validated for use with foreign language speakers in the UK.

Before randomisation, all infants were tested by a trained nurse, using Knobloch, Pasamanick, and Sherard's developmental screening inventory, ${ }^{14}$ to ensure that children with developmental delay were not entered into the study, and to permit later checks for balance between randomised groups.

In one centre the research ethics committee felt that with informed parental consent it was ethical to take blood at randomisation but not analyse it until the end of the study, whereas in the other two it was felt that blood should not be taken unless it was tested at the time. Thus pre-randomisation heel prick blood samples were taken only in Norwich.

Children whose parents came from the Indian subcontinent (a high risk group for iron deficiency ${ }^{15}$ ) were randomised separately to ensure balance between groups. The randomisation schedules were prepared by an independent statistician using permuted blocks of random length. Each centre had a separate schedule and subjects were randomised by the research nurse from consecutively numbered opaque sealed envelopes. Subjects were randomised to cows' milk as before (estimated to contain $0.05 \mathrm{mg}$ iron/litre), formula containing $0.9 \mathrm{mg}$ iron/litre, an otherwise identical formula with $1.2 \mathrm{mg}$ iron/litre as ferrous sulphate, all until 18 months of age. The formula milks were supplied in powdered form; tins of iron fortified formula were labelled "formula 28 " and tins of unfortified formula were labelled "formula 61". This code was not revealed by the manufacturers until the study was completed and all data had been entered and checked. Powdered milk was supplied ad libitum to the subjects' homes, and parents were given written and verbal information on how to make up the milk. Solid foods and other drinks were given as parents chose.

At randomisation, extensive data were collected on birth weight, clinical and feeding history, and social and demographic factors, including birth order, maternal education (coded on the basis of educational attainment ${ }^{16}$ ), and social class, coded according to the occupation of the person who provided financial support for the family. If both parents were in paid employment the father's occupation was coded. ${ }^{17}$ Naked weight was measured using Seca digital baby scales (to the nearest $10 \mathrm{~g}$ ), and triceps and subscapular skinfold thickness using Holtain callipers. Length was measured using a Holtain stadiometer, head circumference and mid-upper arm circumference using a plastic ("lassoo") tape; all to the next mm. At 12 months and 15 months the research nurse visited the home to check on compliance, take a clinical history, and measure children's size as above. Parents were asked to complete a two day food diary at 
Table 1 Studypopulation

\begin{tabular}{|c|c|c|c|}
\hline & Cows'milk & $\begin{array}{l}\text { Unfortified } \\
\text { formula }\end{array}$ & $\begin{array}{l}\text { Iron fortified } \\
\text { formula }\end{array}$ \\
\hline Total number of infants randomised & 166 & 165 & 162 \\
\hline $\begin{array}{l}\text { Stopped assigned milk during the first six months } \\
\text { of the study }\end{array}$ & $7(4 \%)$ & $38(23 \%)$ & $36(22 \%)$ \\
\hline Seen at 18 months & $160(96 \%)$ & $135(82 \%)$ & $133(82 \%)$ \\
\hline
\end{tabular}

randomisation and before each of these visits. Dietary data will be reported separately.

At 18 months children were invited to an assessment by one of four trained follow up staff (GL in Norwich, GM and MQ in Leicester, and CLP in Nottingham), who were blind to the dietary allocation. Children who did not receive the assigned diet throughout the study were invited for assessment in the same way as compliant subjects. If a child had moved home, one of the assessors went to see them, whatever the distance. They were assessed using the motor and mental scales of the Bayley scales of infant development II. ${ }^{18}$ Children were weighed and measured as before and a sample of venous blood was taken from subjects in all centres whose parents consented. In some cases, venepuncture was unsuccessful and blood was then collected by heel prick. The type of sample was recorded. Blood was collected into EDTA tubes and a subsample was taken for measurement of whole blood haemoglobin concentration. In Norwich, blood samples were taken to the laboratories of the Institute of Food Research and in the other centres they were sent to the hospital laboratories, where the subsample was removed. Samples were stored at $-18^{\circ} \mathrm{C}$, then all were analysed in Norwich for haemoglobin, plasma ferritin (by in house enzyme linked immunosorbent assay), and transferrin receptor concentrations ( $\mathrm{R}$ and $\mathrm{D}$ Systems, Abingdon, UK).

The study was designed to have $80 \%$ power to detect an overall five point ( $1 / 3 \mathrm{SD})$ difference in Bayley MDI and PDI at 5\% significance between (1) the iron fortified follow on formula and unfortified formula, and (2) the iron fortified follow on formula and cows' milk by Student's $t$ test. Regression analyses were used to check that all findings

Table 2 Demographics and pre-randomisation measures, at 9 months of age, for children assessed at 18 months

\begin{tabular}{lccc}
\hline & Cows' milk & $\begin{array}{c}\text { Unfortified } \\
\text { formula }\end{array}$ & $\begin{array}{c}\text { Iron fortified } \\
\text { formula }\end{array}$ \\
\hline Birth weight (g) & $3600(470)$ & $3500(450)$ & $3500(510)$ \\
Gestation (weeks) & $39.9(1.4)$ & $39.9(1.3)$ & $39.8(1.4)$ \\
Age in weeks at randomisation & $41.0(1.4)$ & $40.9(1.4)$ & $40.9(1.4)$ \\
Boys (n (\%)) & $91(57)$ & $68(50)$ & $67(50)$ \\
Previously breast fed (n (\%)) & $100(63)$ & $81(60)$ & $83(62)$ \\
Median duration of breast feeding & & & \\
$\quad$ (weeks) (75th centile) & $4(24)$ & $4(16)$ & $4(24)$ \\
First child (n (\%)) & $145(91)$ & $128(96)$ & $122(92)$ \\
Mother had higher education (n (\%)) & $44(28)$ & $29(22)$ & $35(26)$ \\
Non-manual social class (n (\%)) & $71(44)$ & $64(47)$ & $58(44)$ \\
Weight (g) & $9400(1100)$ & $9100(1000)$ & $9200(1200)$ \\
Length (cm) & $72.1(2.5)$ & $71.6(2.6)$ & $71.9(3.0)$ \\
Head circumference (cm) & $46.0(1.4)$ & $45.8(1.4)$ & $45.9(1.4)$ \\
Mid-upper arm circumference (cm) & $15.8(1.4)$ & $15.4(1.3)$ & $15.7(1.4)$ \\
Triceps skinfold thickness (mm) & $12.3(2.8)$ & $11.8(2.9)$ & $11.9(2.6)$ \\
Subscapular skinfold thickness (mm) & $7.7(2.1)$ & $7.6(2.2)$ & $7.7(2.0)$ \\
Developmental score & $99.2(6.0)$ & $99.4(7.5)$ & $99.6(6.7)$ \\
\hline Values are mean (SD) unl & & & \\
\hline
\end{tabular}

Values are mean (SD) unless otherwise stated.

^From Knobloch, Pasamanick, and Sherard's developmental screening inventory. were independent of potentially confounding factors.

Results were analysed on an intention to treat basis, then planned exploratory analyses were performed, including only those children who received the assigned diet for at least six months of the nine month intervention period.

\section{Results}

Initial letters were sent to the families of 11021 infants; $2043(19 \%)$ replied. Of those who replied, $592(29 \%)$ were already feeding whole pasteurised cows' milk; of these 493 (83\%) consented to join our study and were randomised (fig 1). The number of infants recruited and the number not receiving the assigned milk for at least six months are shown for the three diet groups in table 1. Ten children only were recruited from Asian families. Demographic characteristics and baseline developmental scores and anthropometry are shown in table 2 for all children assessed at 18 months of age. Data for those remaining on the study milk for at least six months were very similar. The groups were well balanced, especially in terms of prerandomisation anthropometry and developmental status.

Of those who stopped the assigned diet in the first six months of the study, a significantly higher proportion refused assessment than among those who complied for longer (51 of 81 $(63 \%) v 14$ of $412(3 \%))$. These noncompleting subjects were more likely to come from a lower social class family $(67 \%$ v 55\%; $\mathrm{p}=0.058)$ and have mothers with no educational qualifications $(26 \% \quad v \quad 13 \%$; $\mathrm{p}=0.0026)$. They were lighter at 9 months $(9.0 \approx 9.3 \mathrm{~kg} ; \mathrm{p}=0.05)$ but their developmental scores at randomisation were similar (100.3 v 99.3).

There were a number of anomalous haemoglobin values for children in Nottingham and Leicester and we believe this was because of inadequate mixing of the blood samples when the whole blood aliquots were removed. Haemoglobin results are restricted, therefore, to one centre (Norwich), whereas plasma ferritin and transferrin receptor values are from all centres. Children fed the iron fortified formula had significantly higher mean haemoglobin values and geometric mean plasma ferritin values than those fed the unfortified formula or cows' milk (table 3). There were no significant differences in plasma transferrin receptor values. Among the Norwich cohort at 18 months, $5 \%$ of children on iron fortified formula had a haemoglobin value below $110 \mathrm{~g} /$ litre, compared with $11 \%$ on unfortified formula and $32 \%$ on cows' milk; this difference was not significant.

Table 4 shows intergroup comparisons of mean developmental scores and anthropometry. No significant differences were seen between the high iron (follow on formula) group and either the lower iron formula or cows' milk group. For example, the mean advantages for those fed iron fortified versus unfortified formula were -0.5 (95\% confidence interval (CI), -3.3 to 2.3 ) MDI points 
Table 3 Influence of diet group on haemoglobin, ferritin, and transferrin receptor values at 18 months

\begin{tabular}{llll}
\hline & Cows' milk & $\begin{array}{l}\text { Unfortified } \\
\text { formula }\end{array}$ & $\begin{array}{l}\text { Iron fortified } \\
\text { formula }\end{array}$ \\
\hline $\begin{array}{l}\text { Norwich cohort } \\
\text { Initial haemoglobin (g/1) }\end{array}$ & $\begin{array}{l}99(14) \\
(\mathrm{n}=30)\end{array}$ & $\begin{array}{l}96(11) \\
(\mathrm{n}=27)\end{array}$ & $\begin{array}{l}99(13) \\
(\mathrm{n}=26)\end{array}$ \\
Haemoglobin at 18 months (g/1) & $\begin{array}{l}119(14)^{\star \star} \\
(\mathrm{n}=35)\end{array}$ & $\begin{array}{l}120(11)^{\star} \\
(\mathrm{n}=32)\end{array}$ & $\begin{array}{l}126(11) \\
(\mathrm{n}=40)\end{array}$ \\
$\begin{array}{l}\text { All centres (at 18 months) } \\
\begin{array}{l}\text { Geometric mean plasma ferritin } \\
(\mu \mathrm{g} / \mathrm{l}) \text { (log SD) }\end{array}\end{array}$ & $\begin{array}{l}14.3(0.28)^{\star \star \star} \\
(\mathrm{n}=95)\end{array}$ & $\begin{array}{l}13.1(0.24)^{\star \star \star} \\
(\mathrm{n}=76)\end{array}$ & $\begin{array}{l}21.7(0.22) \\
(\mathrm{n}=90)\end{array}$ \\
$\begin{array}{l}2.49(0.76) \\
\text { Transferrin receptor (mg/1) }\end{array}$ & $\begin{array}{l}2.45(0.83) \\
(\mathrm{n}=88)\end{array}$ & $\begin{array}{l}2.30(0.63) \\
(\mathrm{n}=76)\end{array}$ \\
& $(\mathrm{n}=90)$ & &
\end{tabular}

Values are mean (SD) unless otherwise stated.

Significantly lower than group fed iron fortified formula: ${ }^{\star} \mathrm{p}<0.05,{ }^{\star \star} \mathrm{p}<0.01,{ }^{\star \star \star} \mathrm{p}<0.0001$.

Table 4 Bayley mental and motor developmental indices and anthropometry at 18 months, by diet group

\begin{tabular}{lccr}
\hline & Cows' milk & $\begin{array}{l}\text { Unfortified } \\
\text { formula }\end{array}$ & $\begin{array}{l}\text { Iron fortified } \\
\text { formula }\end{array}$ \\
\hline Intention to treat analysis & 160 & 135 & \\
Number & $96.2(10.4)$ & $94.5(11.7)$ & $93.9(11.7)$ \\
Bayley MDI & $93.6(10.0)$ & $94.6(9.3)$ & $94.8(8.7)$ \\
Bayley PDI & $11400(1400)$ & $11300(1300)$ & $11400(1500)$ \\
Weight (g) & $82.6(3.0)$ & $82.3(2.7)$ & $82.3(3.2)$ \\
Length (cm) & $48.6(1.6)$ & $48.6(1.5)$ & $48.7(1.6)$ \\
Head circumference (cm) & $16.1(1.5)$ & $15.9(1.6)$ & $16.1(1.5)$ \\
Mid-upper arm circumference (cm) & $10.2(2.5)$ & $9.8(2.1)$ & $10.0(2.3)$ \\
Triceps skinfold thickness (mm) & $6.4(1.7)$ & $6.5(1.9)$ & $6.5(1.8)$ \\
Subscapular skinfold thickness (mm) & & & \\
Children who were fed the assigned diet for six or more months & 155 & 120 & 120 \\
Number & $96.1(10.4)$ & $95.0(11.3)$ & $94.1(11.6)$ \\
Bayley MDI & $93.5(9.9)$ & $94.6(9.2)$ & $94.7(8.6)$ \\
Bayley PDI & $11400(1400)$ & $11300(1200)$ & $11400(1600)$ \\
Weight (g) & $82.7(3.0)$ & $82.3(2.7)$ & $82.4(3.2)$ \\
Length (cm) & $48.7(1.6)$ & $48.6(1.5)$ & $48.7(1.6)$ \\
Head circumference (cm) & $16.1(1.5)$ & $15.9(1.6)$ & $16.1(1.4)$ \\
Mid-upper arm circumference (cm) & $10.2(2.5)$ & $9.8(2.0)$ & $10.0(2.3)$ \\
Triceps skinfold thickness (mm) & $6.4(1.7)$ & $6.5(1.9)$ & $6.5(1.8)$ \\
Subscapular skinfold thickness (mm) & & & \\
& & & \\
& & &
\end{tabular}

Values are mean (SD).

MDI, mental developmental index; PDI, psychomotor developmental index.

and 0.2 (95\% CI, -2.0 to 2.4$)$ PDI points. In the comparison between iron fortified formula and cows' milk the advantages of being fed the formula were $-2.3(95 \% \mathrm{CI},-4.8$ to 0.27$)$ MDI points and $1.2(95 \% \mathrm{CI},-0.9$ to 3.4$) \mathrm{PDI}$ points. Very similar results were seen when we analysed only those children who received the assigned diet for at least six months (table 4).

Linear regression models, adjusting for sex, birth order, maternal education, social class, whether breast fed, and pre-randomisation developmental scores did not reveal any significant association between iron supplementation and either Bayley MDI or PDI. In similar analyses including pre-randomisation anthropometry, there was no evidence that iron supplementation influenced growth.

In post hoc analyses, we combined both formula groups and compared formula fed with cows' milk fed children. MDI scores were 2 points lower ( $95 \% \mathrm{CI},-4.2$ to 0.2 ) and PDI scores 1.1 points higher ( $95 \% \mathrm{CI},-0.7$ to 3.0 ) in the children fed formula. Boys fed cows' milk $(n=91)$ rather than formula $(n=135)$ had significantly higher mean Bayley MDI (mean, 95.0; SD, $9.3 v$ mean, 91.6; SD, 11.1; $95 \%$ CI on difference, 0.51 to $6.1 ; \mathrm{p}=0.02$ ). In a regression analysis, an MDI advantage remained for boys fed cows' milk (2.8 points; $95 \%$ CI, 0.01 to 5.6) after adjustment for birth order, social class, maternal education, prerandomisation developmental score, and whether the child was previously breast fed. When boys fed the assigned diet for less than six months were excluded from the regression analysis, the adjusted MDI difference was not significant (2.7 points; $95 \% \mathrm{CI},-0.2$ to 5.5 ). PDI did not differ significantly in similar analyses.

No significant intergroup differences were found for girls.

\section{Discussion}

In our randomised intervention trial we found no benefit, in terms of Bayley MDI or PDI, for children fed a formula with $1.2 \mathrm{mg}$ iron $/ 100 \mathrm{ml}$ (follow on formula), compared with those fed a formula containing $0.9 \mathrm{mg}$ iron $/ 100 \mathrm{ml}$, despite evidence of higher mean serum ferritin values and fewer anaemic children in the group fed follow on milk. Similarly, there was no evidence of a developmental benefit for the group fed iron fortified formula compared with those fed raw pasteurised cows' milk. There was also no evidence of an influence of diet group on growth.

Thus, from a population viewpoint, and on the basis of improved developmental status or growth, our data do not support a routine need for iron supplementation in children between 9 and 18 months, or feeding formula rather than cows' milk. However, it could be argued that because few children in our cohort were anaemic and so most likely to derive developmental benefit from iron supplementation, a substantially larger cohort would have been required to detect the very small likely population difference in developmental scores. It is possible that, within our cohort, children who were anaemic at the start of the study did benefit from supplementation. However, preliminary data for the first 944 subjects in a similar but much larger study in Chile (where there is likely to be a higher incidence of iron deficiency anaemia) demonstrate a significant reduction in anaemia but no advantage in Bayley MDI or PDI at 12 months for children fed iron fortified rather than unfortified formula for six months. ${ }^{19}$ In a parallel study in Chile, children with iron deficiency anaemia at 6 months of age had auditory brainstem responses measured at that age and at 12 and 24 months. At 6 months they had longer central conduction time (indicative of slower or impaired maturation of the auditory system) than controls. Despite effective iron treatment, the disadvantage remained at 12 and 24 months. ${ }^{20}$ These findings support our interpretation of the published data; there is no clear evidence that iron supplementation improves the developmental status of young anaemic children. They also suggest that a crucial period for an adverse effect of iron deficiency on development is before 6 months. This hypothesis needs to be tested formally. An alternative explanation could be that iron deficiency anaemia and delayed maturation of auditory brainstem responses are both related to another unidentified causal factor.

Given the data available when we started our study, and the general belief that iron deficiency anaemia is associated with developmen- 
tal deficit, we felt unable to randomise children we knew to be anaemic. In the UK, children are not screened routinely for anaemia, so it was considered ethical to randomise children without screening. Furthermore, all children were on cows' milk at the start of our study, so no infant was fed milk containing less iron than they would otherwise have received. In only one of the three centres were we permitted by the ethics committee to ask for a blood sample at 9 months and keep it in store until the end of the study. Thus, in two of the three centres we were unable to determine whether children were anaemic at the start of the study, so there were too few subjects to permit exploratory analyses of developmental outcome stratified by initial haemoglobin concentration. Analysis of post-intervention developmental scores by current iron status, rather than by randomised diet group, would be subject to confounding. Even if we had reliable haemoglobin measures for all children at 18 months we do not consider that such an analysis would have added to our understanding of the relation between iron status and development.

In the study by Williams and colleagues, ${ }^{4}{ }^{13}$ $14-15 \%$ of 6 month old infants had a haemoglobin value $<110 \mathrm{~g} /$ litre at recruitment, and $2 \%$ of the iron supplemented formula group and 33\% of the cows' milk fed group were below this value at 18 months. Among the 83 Norwich infants in our study, $84 \%$ had a haemoglobin below $110 \mathrm{~g} /$ litre at 9 months, and $5 \%$ of the iron supplemented formula group and $32 \%$ of the cows' milk fed group were below this value at 18 months. Therefore, the prevalence of anaemia in these two diet groups at 18 months was very similar in the two studies. As in our study, Williams and colleagues found no developmental advantage at 18 months for children fed iron fortified formula versus cows' milk. However, they found that an advantage for the formula group emerged by 24 months. Given the repeated multiple outcome measures, this could be a chance finding, although it is possible that iron supplementation could benefit a domain of development that is better measured with increasing age. Bruner et al showed that in non-anaemic adolescent girls with low serum ferritin, iron supplementation significantly improved verbal learning and memory. ${ }^{21} 22$ Two year old children can be difficult to test and small differences in attention, irritability, or verbal skills may be more influential at 24 than at 18 months, explaining why differences, especially in the personal/social domain, could have emerged at the later age. Further follow up of our cohort to investigate the hypothesis that iron supplementation in early childhood improves later performance in specific domains could help resolve these issues.

In the study by Williams and colleagues, there was no group fed formula without iron supplementation, so an effect of some other dietary factor (such as vitamins added to formula but not cows' milk) could have been responsible for the differences that emerged by 24 months in their formula group. Our data suggest that this is unlikely, because we found no evidence of a developmental advantage for formula fed versus cows' milk fed children.

If iron deficiency is causally related to developmental disadvantage it is unlikely that it would affect all aspects of development. It has long been known that iron is important for central nervous system neurotransmitter function,,$^{23}$ and there is also evidence that iron is essential for normal myelination, ${ }^{25} 26$ being needed for fatty acid and cholesterol synthesis in oligodendrocytes. ${ }^{27}$ Whether standardised global developmental tests like the Bayley scales are sufficiently sensitive to detect specific and relatively subtle differences between treatment groups has been much debated. However, in large randomised intervention trials it would be impossible to use neurophysiological outcome measurements, especially those requiring children to be asleep..$^{20}$ Furthermore, although such measures are of scientific interest, their functional importance for the child is unknown. We found that Bayley MDI at 18 months correlated reasonably well $(r=0.52$; unpublished data, Morley R, 1999) with IQ measured at 7.5-8 years, using an abbreviated form of the Weschler intelligence scales for children. No comparable evidence is yet available for neurophysiological measures.

Safety, as well as efficacy, needs to be considered in relation to providing iron fortified foods to iron sufficient subjects. In a randomised trial giving iron supplementation versus placebo to iron replete $12-18$ month old subjects for four months, Idjradinata et al found that weight gain was reduced in the treated group. ${ }^{28}$ We found no evidence of an adverse effect of nine months of iron supplementation on growth, despite the fact that most of the infants in our study had normal haemoglobin values by 18 months. There is concern that in adults increased iron stores may be more disadvantageous than iron depletion and iron deficiency anaemia. ${ }^{29}$ Patients with iron loading anaemias and genetic haemochromatosis are at risk of organ damage. Observational studies in adults have suggested that high iron stores or high heme iron intake may be associated with increased lipid peroxidation, ${ }^{30}$ cardiovascular disease, and cancer. ${ }^{31}$ Many are unconvinced by these findings, ${ }^{31}$ and their relevance in very young children is uncertain. Nevertheless, further work is required on the safety aspects of raising iron intake in iron sufficient children.

Larger intervention trials in anaemic infants, with adequate sample size to detect plausible and clinically relevant differences in appropriate outcome measures, need to be undertaken to resolve the issue of whether iron status and development are causally related. ${ }^{32}$

We thank Wyeth Laboratories for funding this study, the research nurses (M Alty, E Crowe, and S Sills), staff at the Food Reseach Institute for haematological assays (J Belsten and C Phillips), the doctors who conducted the follow up examinations (C Leeson Payne, G Lister, G McHugh, and M Quinn), and the children and parents who generously agreed to take part in this study.

1 DeMaeyer E, Adiels-Tegman M. The prevalence of anaemia in the world. World Health Stat Q 1985;38:302-16. 
2 Cook JD. Iron-deficiency anaemia. Baillieres Clin Haematol 1994;7:787-804.

3 Stevens D, Nelson A. The effect of iron in formula milk after 6 months of age. Arch Dis Child 1995;73:216-20.

4 Daly A, MacDonald A, Aukett A, et al. Prevention of anaemia in inner city toddlers by an iron supplemented cow's milk formula. Arch Dis Child 1996;75:9-16.

5 Hertrampf E, Olivares M, Pizarro F, et al. Haemoglobin fortified cereal: a source of available iron to breast-fed infants. Eur 7 Clin Nutr 1990;44:793-8.

6 Lozoff B, Jimenez E, Wolf AW. Long-term developmental outcome of infants with iron deficiency. $N$ Engl $\mathcal{F} \mathrm{Med}$ 1991;325:687-94.

7 Walter T. Impact of iron deficiency on cognition in infancy and childhood. Eur f Clin Nutr 1993;47:307-16.

8 Lozzoff B, Wolf AW, Jiminez E. Iron-deficiency anemia and infant development: effects of extended oral iron therapy. $\mathcal{F}$ Pediatr 1996;129:382-9.

9 Simeon DT, Grantham-McGregor SM. Nutritional deficiencies and children's behaviour and mental development. ciencies and children's behaviour and mentition Research Reviews 1990;3:1-24.
Nutrit.

10 Aukett MA, Parks YA, Scott PH, Wharton BA. Treatment with iron increases weight gain and psychomotor developwith ir A increases weight gain

11 Idjradinata P, Pollitt E. Reversal of developmental delays in iron-deficient anaemic infants treated with iron. Lancet 1993;341:1-4.

12 Moffatt ME, Longstaffe S, Besant J, Dureski C. Prevention of iron deficiency and psychomotor decline in high risk infants through use of iron fortified formula: a randomised trial. I Pediatr 1994;125:527-34.

13 Williams J, Wolff A, Daly A, MacDonald A, Aukett A, Booth IW. Iron supplemented formula milk related to reduction in psychomotor decline in infants from inner city areas: randomised study. BMF 1999;318:693-8.

14 Knobloch H, Pasamanick B, Sherard ES. A developmental screening inventory for infants. Pediatrics 1966;38(suppl): 1095-108.

15 Marder E, Nicoll A, Polnay L, Shulman CE. Discovering anaemia at child health clinics. Arch Dis Child 1990;65: 892-4.

16 Lucas A, Cole TJ, Morley R, et al. Factors associated with maternal choice to provide breast milk for low birthweight infants. Arch Dis Child 1988;63:48-52.

17 Registrar General's classification of occupations. London: HMSO.

18 Bayley scales of infant development, 2nd ed. San Antonio: The Psychological Corporation, 1993.
19 Lozoff B, De Andraca I, Walter T, Pino P. Does preventing iron deficiency anemia improve developmental test scores? [abstract]. Pediatr Res 1996;39:136A.

20 Roncagliolo M, Garrido M, Walter T, Peirano P, Lozoff B. Evidence of altered central nervous system development in infants with iron deficiency anaemia at 6 mo: delayed maturation of auditory brainstem responses. Am $\mathcal{F}$ Clin Nutr 1998;68:683-90.

21 Bruner AB, Joffe A, Duggan AK, Casella JF, Brandt J. Randomised study of cognitive effects of iron supplementation in non-anaemic iron-deficient adolescent girls. Lancet 1996;348:992-6.

22 Ashby D. Can iron supplementation improve cognitive functioning? Lancet 1996;348:973.

23 Youdim $\mathrm{MBH}$. Neuropharmacological and neurobiochemical aspects of iron deficiency. In: Dobbing J, ed. Brain, behaviour and iron in the infant diet. London: SpringerVerlag, 1990:83-106.

24 Beard JL, Connor JR, Jones BC. Iron in the brain. Nutr Rev 1993;51:157-70.

25 Connor JR, Benkovic SA. Iron regulation in the brain: histochemical, biochemical and molecular considerations. Ann Neurol 1992;32:S51-61.

26 Connor JR, Menzies SL. Altered cellular distribution of iron in the central nervous system of myelin deficient rats. Neuroscience 1990;34:265-71.

27 Larkin EC, Rao GA. Importance of fetal and neonatal iron: adequacy for normal development of central nervous system. In: Dobbing J, ed. Brain, behaviour and iron in the infant diet. London: Springer-Verlag, 1990:43-62.

28 Idjradinata P, Watkins WE, Pollitt E. Adverse effect of iron supplementation on weight gain of iron-replete young children. Lancet 1994;343:1252-4.

29 Marx JJM. Iron deficiency in developed countries: prevalence, influence of lifestyle factors and hazards of prevention. Eur f Clin Nutr 1997;51:491-4.

30 Salonen JT. Body iron stores, lipid peroxidation and coronary heart disease. In: Hallberg L, Asp N-G, eds. Iron nutrition in health and disease. London: Libbey, 1996:293-301.

31 Ascherio A, Willett WC. Epidemiological studies relating iron status to coronary heart disease and cancer. In: Hallberg L, Asp N-G, eds. Iron nutrition in health and disease. London: Libbey, 1996:303-11.

32 Logan S. Iron deficiency and developmental deficit-the ury is still out. BMf 1999;318:697-8. 